\title{
Quality of rehabilitation among workers with adjustment disorders according to practice guidelines; a retrospective cohort study
}

\author{
K Nieuwenhuijsen, J H A M Verbeek, J C M J Siemerink, D Tummers-Nijsen
}

Occup Environ Med 2003;60(Suppl I):i2 1-i25

See end of article for authors' affiliations

\section{Correspondence to:} Drs K Nieuwenhuijsen, Coronel Institute for Occupational and Environmental Health Academic Medical Center, University of Amsterdam, PO Box 22700, 1100 DD Amsterdam, Netherlands; K.Nieuwenhuijsen@ amc.uva.nl

Accepted

11 October 2002

\begin{abstract}
Aims: To assess the quality of occupational rehabilitation for patients with adjustment disorders and to determine whether high quality of care is related to a shorter period of sickness absence.

Methods: A retrospective cohort study was conducted by means of an audit of 100 files of patients with adjustment disorders who visited their occupational physicians. Quality of rehabilitation was assessed by means of 10 performance indicators, derived from the guidelines for the treatment of employees with mental health disorders. Performance was dichotomised into optimal and deviant care according to explicit criteria. The performance rates were related to time until work resumption during a one year follow up period. Kaplan-Meier survival analyses and Cox proportional hazards analysis were used to study this relation.

Results: Four of 10 performance rates were below $50 \%$ : continuity of care $(34 \%)$, interventions aimed at providers of care in the curative sector $(39 \%)$, assessment of impediments in the return to work process $(41 \%)$, and assessment of symptoms $(45 \%)$. The highest performance rate concerned assessment of work related causes $(94 \%)$. Overall optimal care was found in $10 \%$ of the cases. Median time to complete recovery was 195 days (IQR 97 to 365), and 73\% of all patients recovered completely after one year. Optimal continuity of care was significantly related to a shorter time to both partial and complete work resumption (hazard ratio (HR) $0.3 ; \mathrm{Cl} 0.2$ to 0.6 ) independently of other performance indicators. Performance regarding interventions aimed at the organisation was also related to a shorter time until first return to work (HR 0.5; $\mathrm{Cl} 0.3$ to 0.9$)$.

Conclusions: This study shows that the rehabilitation process of employees with adjustment disorders leaves significant room for improvement, especially with regard to continuity of care. Quality of care was partly related to a better outcome. More rigorous study designs are needed to corroborate these findings.
\end{abstract}

W rk disability as a result of mental health problems accounts for $30 \%$ of all disability benefits in the Netherlands. A majority (69\%) of those employees suffer from minor psychiatric disorders such as adjustment disorders. ${ }^{1}$ Adjustment disorder is a diagnosis that can be found in both the DSM IV and ICD-10 classification systems. It refers to a maladaptive reaction to an identifiable stressor. It is characterised either by significant impairment in social or occupational functioning, or by marked excessive subjective stress. ${ }^{23}$ The symptoms usually resolve within six months. All employees receiving disability benefits have been on sick leave for at least one year. This means that the duration of sick leave for this group is longer than may be expected.

In the Netherlands, employees who are absent from work because of sickness are required to visit their occupational physician for rehabilitation purposes. The occupational physician therefore plays an important role in the rehabilitation process. However, little is known about the quality and effectiveness of this process. ${ }^{4}$

\section{Main messages}

- Quality of occupational rehabilitation can be improved, especially with regard to continuity of care and interventions aimed at providers of care in the curative sector.

- Optimal continuity of care is related to a shorter duration of sickness absence for employees with adjustment disorders.

- Most aspects from the practice guidelines were not related to outcome, indicating that more research is needed to show that these guidelines also lead to better outcome in terms of return to work.
In 2000, the Dutch Association for Occupational and Industrial Medicine (NVAB) published practice guidelines for the rehabilitation of employees with adjustment disorders. ${ }^{5}$ The practice guidelines support occupational physicians with instructions on desired rehabilitation activities. Up till now, no evaluation of these practice guidelines has been conducted.

A study on the rehabilitation of workers with low back pain showed that it is possible to assess the quality of care provided by occupational physicians. ${ }^{6}$ This evaluation was conducted by deriving performance indicators from practice guidelines and formulating explicit criteria for each of these indicators. One important finding was that good quality of care was associated with a shorter duration of the sickness absence. ${ }^{7}$ Recently, performance indicators were developed to measure quality of occupational rehabilitation for workers with mental health problems. $^{8}$

Evaluation of quality of care can be conducted by means of an audit. An audit is defined as "a systematic critical analysis of the quality of medical care, including the procedures used in diagnosis and treatment, the use of resources, and the resulting outcome for the patient". ${ }^{\text {. }}$ The publication of practice

\section{Policy implications}

- Quality of occupational rehabilitation should be improved by providing more continuity of care for employees with adjustment disorders.

- There is a need for more research focusing on the effectiveness of occupational rehabilitation with work resumption as outcome.

- Occupational physicians should confer with employers more often in order to achieve a more rapid return to work. 
Table 1 Performance indicators (PI) and criteria for rehabilitation of workers with adjustment disorders

\begin{tabular}{|c|c|}
\hline PI 1 & $\begin{array}{l}\text { Quality of the assessment of symptoms } \\
\bullet \geqslant 3 \text { symptoms noted in medical file }\end{array}$ \\
\hline PI 2 & $\begin{array}{l}\text { Correct diagnosis } \\
\text { - a diagnosis should be noted in the file } \\
\text { If } \geqslant 5 \text { depressive symptoms (including } \geqslant 1 \text { obliged symptom) are noted in file, then } \\
- \text { diagnosis should be depressive disorder } \\
\text { If } \geqslant 3 \text { anxiety symptoms (including } \geqslant 1 \text { obliged symptom) are noted in file, then } \\
\text { - diagnosis should be anxiety disorder } \\
\text { If diagnosis is depressive disorder, not anxiety disorder and } \geqslant 4 \text { distress symptoms are } \\
\text { noted, then } \\
\text { - diagnosis should be adjustment disorder }\end{array}$ \\
\hline PI 3 & $\begin{array}{l}\text { Evaluation of the treatment in the curative sector } \\
\text { - treatment, or its absence, should be noted in file } \\
\text { If patient is under treatment, then } \\
\text { - this treatment should be described }\end{array}$ \\
\hline PI 4 & $\begin{array}{l}\text { Assessment of work related causes } \\
\text { - the work related causes, or their absence, should be stated in the medical file }\end{array}$ \\
\hline PI 5 & $\begin{array}{l}\text { Assessment of impediments in the return to work process } \\
\text { - the impediments, or their absence, should be stated in the medical file }\end{array}$ \\
\hline PI 6 & $\begin{array}{l}\text { Interventions aimed at the individual } \\
\text { If diagnosis is adjustment disorder, then } \\
\text { - an intervention aimed at the individual should be noted in the file } \\
\text { OR } \\
\text { - patient should be referred to psychologist/social worker/general practitioner }\end{array}$ \\
\hline $\mathrm{PI} 7$ & $\begin{array}{l}\text { Interventions aimed at the organisation } \\
\text { If work related causes or impediments to return to work process are present, then } \\
\text { - the occupational physician should confer with superior or personnel officer }\end{array}$ \\
\hline PI 8 & $\begin{array}{l}\text { Interventions aimed at providers of care in the curative sector } \\
\text { If treatment in curative sector is inadequate, then } \\
\text { - patient should be referred to psychologist/social worker/general practitioner }\end{array}$ \\
\hline PI 9 & $\begin{array}{l}\text { Timing of the first consultation } \\
\text { - first consultation should be within } 3 \text { weeks from first day of sickness absence }\end{array}$ \\
\hline PI 10 & $\begin{array}{l}\text { Continuity of care } \\
\text { If patient has not yet completely recovered, then } \\
\text { - second consultation should be within } 3 \text { weeks from first consultation } \\
\text { AND } \\
\text { - third consultation should be within } 3 \text { weeks from second consultation }\end{array}$ \\
\hline
\end{tabular}

guidelines enables an audit of occupational rehabilitation for employees with adjustment disorders.

We conducted an audit of medical files. Work resumption of the patient was considered the final outcome of the rehabilitation process. Therefore, the aim of this study is twofold: (1) to assess the quality of occupational rehabilitation of patients with adjustment disorders; and (2) to determine whether high quality of care is related to the length of sickness absence.

\section{METHODS}

\section{Subjects}

The present study is a retrospective cohort study of patient files with a one year follow up period. The cohort was defined as the first 100 patients on sick leave because of adjustment disorders who visited their occupational physician in the years 1999 and 2000. Other inclusion criteria were: first time visit to an occupational physician since the onset of the sickness absence; 100\% absent from work; no major psychiatric disorder such as a depressive disorder; and no prominent somatic disorders.

\section{Clinical guidelines}

The guidelines provide instructions on five aspects of the occupational rehabilitation process. The occupational physi- cian should: (1) assess psychological symptoms and impairments of occupational functioning; (2) distinguish an adjustment disorder from major psychiatric disorders such as depressive or anxiety disorder; (3) evaluate the effectiveness of treatment conducted in the curative sector; (4) assess all impediments in the return to work process; and (5) carry out interventions aimed at either the employee (for example, using cognitive-behavioural techniques) or the workplace (for example, advice on a gradual return to work).

\section{Measures}

Independent variables

Quality of the occupational rehabilitation process

Table 1 shows the performance indicators used to measure quality. The majority of the criteria are based on an if-then logic. For instance, if the employee experiences work related problems, then the occupational physician should intervene in the organisation. If a criterion was not met, the case was assigned 1 for that performance indicator. If all applicable criteria for a performance indicator were met, the resulting score was 0 for that case.

For each performance indicator, a performance rate was calculated as the number of patients who received care consistent with the guidelines, divided by the total number of 
patients. Furthermore, a total score of all performance indicators was calculated which we called overall quality of care. Finally, overall quality of care was dichotomised into overall deviant and overall optimal care. Overall quality of care was considered deviant if three or more performance indicators were assigned a score of 1 , and optimal if less than three performance indicators had a score of 1 .

\section{Dependent variables}

Return to work

Occupational health services routinely register sickness absence based on information provided by employers. This registration enabled us to measure both number of days until first return to work (usually meaning partial return to work) and number of days until complete recovery (working as many hours as before the onset of the sickness absence).

\section{Potential confounders}

Age, gender, occupation, and severity of the disorder were checked for possible confounding. A confounder was defined as a potentially prognostic factor that was both predictive for return to work and related to performance at a significance level of $\mathrm{p}<0.10$. We categorised occupation on the basis of job title into groups of mentally demanding work, mixed mentally and physically demanding work, and physically demanding work. ${ }^{10}$ The subcategory burnout was used as an indicator for severity. Although burnout is not a diagnosis present in DSM-IV or ICD-10, it is usually classified as an adjustment disorder. However, burnout is considered a more severe disorder, with symptoms accumulating for at least a year. ${ }^{5}$ Three types of symptoms characterise burnout: symptoms of serious emotional exhaustion accompanied by either distant feelings or cynicism in relation to others, or reduced feelings of personal accomplishment. ${ }^{11}$

\section{Procedure}

We used recordings of the first two consultations for each file. A consultation was defined as a personal contact between occupational physician and patient, either by telephone or a face to face contact. Information on the rehabilitation process was abstracted from the medical files using a registration form. This form was designed to enable a complete assessment of all the performance criteria. Two researchers independently filled out the registration forms, both being instructed on the interpretation of common phrases and synonyms used by the occupational physicians. The two researchers discussed all cases that were not initially agreed on until consensus was reached.

\section{Statistical analysis}

Univariate analyses

A Kaplan-Meier survival curve was estimated to describe the univariate relations between performance and time until work resumption. Differences were tested using the log rank test.

\section{Multivariate analyses}

Cox's proportional hazards analysis was used to describe the multivariate associations between performance and both time to first return to work and time to complete recovery. All performance indicators that showed sufficient variability (less than $90 \%$ of patients with the same score) were selected for these analyses. In order to adjust the results, any identified confounder was to be introduced into the multivariate model. All variables were entered into the model in a single step (method:enter). Analyses were performed using the SPSS 10.0 software package (SPSS Inc., Illinois, USA).

\section{RESULTS}

\section{Patient characteristics}

Table 2 presents the characteristics of the 100 employees. They were treated by 35 different occupational physicians.
Table 2 Characteristics of employees with adjustment disorders $(n=100)$

\begin{tabular}{ll}
\hline Sociodemographic & \\
Gender, female (\%) & 60 \\
Age, mean years (SD) & $44(9)$ \\
Occupation & 36 \\
$\quad$ Mentally demanding (\%) & 15 \\
Physically demanding (\%) & 41 \\
Mixed tasks (\%) & 8 \\
Unknown (\%) & \\
Disorder and absence related & \\
Specific diagnosis within group of adjustment disorders & 12 \\
$\quad$ Burnout (\%) & 88 \\
$\quad$ Other minor psychiatric disorder (\%) & $22(12-35)$ \\
Days until first consultation, median (IQR) & $5(3)$ \\
Number of consultations with occcupational \\
physician, mean (SD) \\
Duration of sick leave in days, median (IQR) \\
$\quad$ First return to work \\
Complete recovery & $94(54-195)$ \\
\hline
\end{tabular}

*Follow up period was one year, therefore 365 days means 365 days or more.

Table 3 Performance rates of rehabilitation procedures per patient $(n=100)$

\begin{tabular}{ll}
\hline Performance indicator & $\begin{array}{l}\text { Rate of optimal } \\
\text { performance }\end{array}$ \\
\hline PI 1: Assessment of symptoms & 45 \\
PI 2: Correct diagnosis & 76 \\
PI 3: Evaluation curative care & 60 \\
PI 4: Assessment work related causes & 94 \\
PI 5: Assessment of impediments in return to work & 41 \\
process & 52 \\
PI 6: Interventions aimed at individual & 70 \\
PI 7: Interventions aimed at organisation & 39 \\
PI 8: Interventions aimed at providers of care in & \\
curative sector & 50 \\
PI 9: Timing of first consultation & 34 \\
PI 10: Continuity of care & 10 \\
Overall performance (<3 Pls with deviant care) &
\end{tabular}

\section{Quality of occupational rehabilitation}

Table 3 shows the performance rates. Low performance rates on the assessment of both symptoms and impediments in the return to work process were the result of an incomplete assessment or a lack of information on those topics in the medical file. The low performance rate of continuity of care was mainly caused by the fact that the time period between the second and third consultation was too long, or that no new appointment had been made. Assessment of work related causes showed the highest performance rate.

\section{Return to work}

After one year follow up, $84 \%$ had partially returned to their jobs and $73 \%$ had completely recovered. Time to first return to work ranged from 7 to 365 days, with a median of 94 days. Time to complete recovery had the same range, but a median of 195 days.

\section{Univariate analyses of relation between performance and return to work}

No significant relation between overall performance and time until work resumption was found. Deviant care on "interventions aimed at the organisation" $(\mathrm{p}=0.02)$ and "continuity of care" $^{\prime \prime}(\mathrm{p}<0.0001)$ was significantly related to a longer time until a first return to work. Deviant continuity of care was also significantly related to a longer time until complete recovery $(p<0.0001)$. Subjects older than 50 years took longer to reach 
Table 4 Cox proportional hazards analysis of occupational physician performance in occupational rehabilitation of employees with adjustment disorders $(n=100)$

\begin{tabular}{|c|c|c|}
\hline $\begin{array}{l}\text { Performance indicator } \\
\text { Deviant care: }\end{array}$ & $\begin{array}{l}\text { First return to work } \\
\text { Hazard ratio }(95 \% \mathrm{Cl})\end{array}$ & $\begin{array}{l}\text { Complete recovery } \\
\text { Hazard ratio }(95 \% \mathrm{Cl}\end{array}$ \\
\hline Assessment of symptoms & $1.0(0.7$ to 1.6$)$ & $1.1 \quad(0.7$ to 1.9$)$ \\
\hline Correct diagnosis & $1.6(0.9$ to 2.9$)$ & 1.2 (0.6 to 2.2$)$ \\
\hline Evaluation curative care & $1.2(0.7$ to 1.8$)$ & $1.5(0.9$ to 2.4$)$ \\
\hline Assessment work related causes & $\dagger$ & $\dagger$ \\
\hline Assessment of impediments & $1.0(0.6$ to 1.6$)$ & $1.0(0.7$ to 1.8$)$ \\
\hline Interventions aimed at individual & $1.0(0.5$ to 2.0$)$ & $1.3(0.6$ to 2.9$)$ \\
\hline Interventions aimed at organisation & $0.5(0.3 \text { to } 0.9)^{*}$ & $1.2(0.7$ to 2.1$)$ \\
\hline Interventions aimed at providers of care in the curative sector & $1.2(0.6$ to 2.4$)$ & 1.0 (0.5 to 2.2$)$ \\
\hline Timing of first consultation & $0.8(0.5$ to 1.2$)$ & $0.7(0.5$ to 1.2$)$ \\
\hline Continuity of care & $0.3(0.2 \text { to } 0.5)^{*}$ & $0.3(0.2 \text { to } 0.5)^{*}$ \\
\hline
\end{tabular}

complete recovery $(\mathrm{p}=0.02)$, but did not differ from younger employees on first return to work. None of the potential confounders were related to outcome and were therefore not included in the multivariate model

\section{Multivariate analyses of relations between performance and return to work}

Table 4 shows the results of the Cox proportional hazard analysis. A hazard ratio of less than 1 indicates that the performance indicator is associated with a longer time to return to work. The performance indicator work related causes was not included in the analysis because of insufficient variance. Deviant care on "interventions aimed at the organisation" (hazard ratio (HR) 0.5 ; CI 0.3 to 0.9 ) and "continuity of care" (HR 0.3: CI 0.2 to 0.5 ) was significantly related to a longer time until a first return to work. Deviant continuity of care (HR 0.3 ; CI 0.2 to 0.5 ) was also significantly related to a longer time until complete recovery.

\section{DISCUSSION}

Our study shows that the quality of occupational rehabilitation of employees with adjustment disorders did not fully meet the requirements of the practice guidelines. In line with our hypothesis, we found that optimal performance on interventions aimed at the organisation and continuity of care was related to a shorter duration of the sickness absence. However, we did not find a relation between performance and outcome for the other performance indicators, nor for overall performance.

In 1993, Schröer found a return to work rate of $75 \%$ after one year in a cohort similar to ours. ${ }^{12}$ However, only $40 \%$ of all employees had access to occupational health care in 1993, whereas all employees on sick leave are currently obliged to visit their occupational physician. It seems that the increase in access to occupational health care has not yet resulted in more favourable return to work rates for workers with adjustment disorders.

This audit took place around the time of authorisation of the guidelines. Because our study shows that daily practice at that time did not meet the requirements of the practice guidelines, an extensive implementation programme is needed. Until now, the implementation has been limited to passive education techniques such as lectures and publications. A review of literature on strategies to change physician performance has shown that more active methods, such as reminders and outreach visits, are more effective. ${ }^{13}$ Future research should aim at the effectiveness of the implementation of the practice guidelines. Our performance indicators could be useful tools in this implementation process.

Our finding that optimal continuity of care is related to a shorter duration of sickness absence is consistent with a study of patients with low back pain. ${ }^{7}$ Patients who received good continuity of care returned to work 61 days sooner than those who did not. Although employees seem to benefit from continuity of care, it is also possible that patients with favourable prognoses were seen more regularly. However, we were able to adjust the results for the influence of severity of the disorder. Still, other factors might have influenced both prognosis and continuity of care.

Several factors might have contributed to long intervals between consultations. Firstly, many employers buy a minimum of services from the occupational health service and do not provide for regular consultations. ${ }^{14}$ Secondly, the occupational health services may have long waiting lists because of a shortage of occupational physicians. Finally, setting a date for the next consultation is usually a result of mutual agreement between patient and occupational physician. Therefore, we believe that enhancing continuity of care is a collective responsibility of the employer, the occupational health service, the occupational physician, and the patient.

Our findings suggest that interventions aimed at the organisation, such as conferring with supervisors or personnel officers, are effective in enhancing first return to work. However, interventions are undertaken in only $30 \%$ of the cases where work related causes or impediments in the return to work process are present. Occupational physicians should therefore be encouraged to intervene more often.

Contrary to our expectations, most performance indicators were not related to outcome. The finding that interventions aimed at the individual were not effective in enhancing return to work was particularly unexpected. Individual interventions such as applying cognitive-behavioural techniques are effective in symptom reduction according to a meta-analysis of the literature. ${ }^{15}$ An explanation for our findings could be that, although employees may benefit from such interventions, it does not necessarily mean that they return to their jobs. This is in line with the finding that symptom reduction and work resumption are only weakly related in employees with both major depressive disorders ${ }^{16}$ and psychotic affective disorders. ${ }^{17}$ Work resumption should therefore be incorporated as an outcome measure in effectiveness studies more often.

Two aspects of our study may have contributed to the absence of a relation between most indicators and outcome. First, our criteria may not adequately reflect the practice guidelines. Contrary to this argument, occupational physicians and the guideline committee considered our performance indicators and criteria to be an accurate reflection of the practice guidelines. Moreover, our cut off point for overall good or deviant performance was arbitrary and may have lacked clinical relevance.

An audit of medical files is, as with any observational study, susceptible to bias. A first possible source of bias is that physicians did not register all their findings systematically for use in research. Negative findings and routine activities may not 
have been recorded, thereby resulting in an underestimation of the true performance. In this respect it should be noted that the lowest performance rate was that of continuity of care. The occupational health service routinely lists the date of each consultation, which rules out the possibility of inaccurate registration. Data extraction was subject to interpretation by the researchers, which may have been a second source of bias. However, the two researchers independently abstracted data from the patient files. A third possible source of bias consisted of unknown potential confounders. We were only able to check the influence of four factors: age, gender, occupation, and severity of the disorder.

In contrast, our findings are unlikely to be biased as a result of selection, as the occupational physicians could not influence the inclusion of files. Furthermore, the occupational physicians were unaware that their notes would be used for research purposes and were therefore unbiased in their registration. The cohort was followed for a sufficiently long period, during which most subjects had returned to work.

Apart from these methodological considerations, a critical reappraisal of the guidelines may be needed since the practice guidelines are more consensus based than evidence based. Consensus based guidelines are phases in an ongoing process of achieving higher quality of care. ${ }^{18}$ More research, preferably randomised trials, is needed to show that these guidelines also lead to a better outcome in terms of return to work.

\section{Conclusion}

This study shows that the rehabilitation process of employees with adjustment disorders could be improved. More regular contacts with an occupational physician and appropriate interventions aimed at the organisation seem to result in a shorter duration of sickness absence. A relation between the other performance indicators and outcome could not be established. These results suggest that the guidelines could improve the effectiveness of occupational rehabilitation among workers with adjustment disorders. Studies with methodologically more rigorous study designs are needed to corroborate these findings.

\section{ACKNOWLEDGEMENTS}

Grants were obtained from: The Netherlands Organization for Scientific Research (NWO): Netherlands Concerted Research Action "Fatigue at Work"; and the Foundation for Replacement and Occupational Health in Education (Stichting Vf/BGZ).

\section{Authors' affiliations}

K Nieuwenhuijisen, J H A M Verbeek, Coronel Institute for Occupational and Environmental Health, Academic Medical Center, AmCOGG, University of Amsterdam, Netherlands

J C M J Siemerink, De Boer en Rienks Occupational Health Service, Houten, Netherlands

D Tummers-Niisen, ArboNed Occupational Health Service, Venlo, Netherlands

\section{REFERENCES}

1 LISV. Ziektendiagnoses bij vitkeringen voor arbeidsongeschiktheid [diagnoses of disability benefit recipients]. Amsterdam: LISV (Landelijk Instituut Sociale Verzekeringen), 2000.

2 American Psychiatric Association. Diagnostic and statistical manual of mental disorders, 4th edn. Washington, DC: APA, 1994

3 Bramer GR. International statistical classification of diseases and related health problems. Tenth revision. World Health Stat Q 1988;41:32-6.

4 Hulshof CT, Verbeek JH, Dijk FJ van, et al. Evaluation research in occupational health services: general principles and a systematic review of empirical studies. Occup Environ Med 1999;56:361-77.

5 Dutch Association for Occupational and Industrial Medicine (NVAB). Guidelines for the rehabilitation of employees with mental health disorders. Eindhoven: NVAB, 2000

6 Weide WE van der, Verbeek JHAM, et al. The development and evaluation of a quality assessment instrument for occupational physicians. Occup Environ Med 1998:55:375-82.

7 Weide WE van der, Verbeek JHAM, Dijk FJH van. Relation between indicators for quality of occupational rehabilitation of employees with low back pain. Occup Environ Med 1999;56:488-93

8 Smits PBA, Buisonjé CD de, Verbeek JHAM, et al. Is problem-based learning more effective than lecture-based learning in postgraduate medical education? A randomized controlled trial. Submitted, 2002.

9 Agius RM, Seaton A, Lee R. Audit of sickness absence and fitness-for-work referrals. Occup Med 1995;45:125-30.

10 De Zwart BCH, Broersen JPJ, Beek AJ van der, et al. Occupational classification according to work demands: an evaluation study. Int J Occup Med Environ Health 1997; 10:283-95.

11 Maslach C, Schaufeli WB, Leiter MP. Job burnout. Annu Rev Psychol 2001;52:397-422

12 Schroër CAP. Ziekteverzuim wegens overspanning [absenteeism due to 'overstrain']. Maastricht: UM, 1993.

13 Davis DA, Thomson MA, Oxman AD, et al. Changing physician performance. A systematic review of the effect of continuing medical education strategies. JAMA 1995;274:700-5.

14 Schaufeli WB, Kompier MA. Managing job stress in the Netherlands. International Journal of Stress Management 2001;8:15-34.

15 Klink JJL van der, Blonk RWB, et al. The benefits of interventions for work-related stress. Am J Public Health 2001;91:270-6.

16 Mintz J, Mintz LI, Arruda M, et al. Treatments of depression and the functional capacity to work. Arch Gen Psychiatry 1992;49:761-8.

17 Tohen M, Hennen J, Zarate CM, et al. Two-year syndromal and functional recovery in 219 cases of first-episode major affective disorder with psychotic features. Am J Psychiatry 2000;157:220-8.

18 Agius RM. Auditing occupational medicine. Occup Med (Lond) 1999;49:261-4. 